\title{
Artigos
}

\section{Reformulação curricular dos cursos de Terapia Ocupacional: resultados e desafios de um percurso}

\author{
Curricular reformulation of Occupational Therapy courses: results and \\ challenges of a trajectory (abstract: p. 16)
}

Reformulación curricular de los cursos de Terapia Ocupacional: resultados y desafíos de un recorrido (resumen: p. 16)

\author{
Ana Beatriz Zimmermann ${ }^{(a)}$ \\ <anabeatriz@ufpr.br> iD \\ Adriana Belmonte Moreira ${ }^{(b)}$ \\ <adriana.belmonte@ufpr.br> (iD) \\ Derivan Brito da Silva ${ }^{(c)}$ \\ <derivan@ufpr.br> \\ Iranise Moro Pereira Jorge ${ }^{(d)}$ \\ <iranise@ufpr.br> \\ Maria Jose Gugelmin De Camargo(e) \\ <mariajosegugelmin@hotmail.com> \\ Milton Carlos Mariotti ${ }^{(f)}$ \\ <mariotti@ufpr.br> (i) \\ (continua p. 13)
}

Este artigo relata o processo de reformulação curricular do Curso de Terapia Ocupacional da Universidade Federal do Paraná ocorrido no período de 2013 a 2016. As justificativas para a reformulação foram: a necessidade de alinhamento com as atuais políticas públicas nacionais e os parâmetros nacionais e internacionais para formação profissional. 0 processo ocorreu de modo participativo e problematizador, culminando em uma matriz curricular delineada por eixos e ênfases específicas, com 3.305 horas distribuídas em cinco anos. A proposta pedagógica contempla a diversidade teórico-prática e didático-metodológica dos docentes. Consideraram-se também: a especificidade da formação em período noturno, o perfil dos estudantes ingressantes, a necessidade de redução nos índices de retenção e evasão, e as mudanças no mercado de trabalho. 0 desafio agora é a implantação gradativa e a avaliação continuada do novo currículo, de modo a garantir a formação esperada.

Palavras-chave: Currículo. Terapia Ocupacional. Ensino superior. 


\section{Introdução}

Este trabalho tem por objetivo apresentar o processo de Reformulação do Projeto Pedagógico (RPP) dos Cursos de Graduação em Terapia Ocupacional (CGTO) da Universidade Federal do Paraná (UFPR). Conduzido por meio de uma metodologia problematizadora, o processo culminou em um projeto pedagógico que propóe um percurso formativo vertical e horizontal delineado por ênfases e eixos temáticos, em consonância com o núcleo conceitual e técnico-científico da profissão e com base nos princípios éticos e formativos preconizados pelo plano de desenvolvimento institucional ${ }^{1}$.

O curso integral de Terapia Ocupacional da UFPR foi implantado em 2001, reconhecido pelo Ministério da Educação (MEC) em 2004 e credenciado junto à World Federation of Occupational Therapists (WFOT) em 2005. No ano de 2006, houve a primeira reformulação curricular do curso, com ajustes posteriores. Em 2007, a UFPR aderiu ao Programa de Apoio a Planos de Reestruturação e Expansão das Universidades Federais (REUNI), sendo definidas naquele momento: a ampliação de vagas ofertadas no curso integral e a abertura de um curso noturno. A partir de 2009, o curso integral aumentou a oferta de 30 para 60 vagas e, no segundo semestre de 2011, houve o ingresso da primeira turma noturna, totalizando 120 vagas anuais. Os CGTO contam com: 23 docentes, quatro técnicos em educação vinculados ao Departamento de Terapia Ocupacional e dois técnicos administrativos.

O processo vivenciado com ampliação da oferta de vagas e a abertura do curso noturno possibilitou apurar a reflexão sobre as necessidades de atualização curricular. Diante da realidade dos CGTO com novo perfil de estudantes ingressantes e das mudanças políticas, educacionais e sociais, o Núcleo Docente Estruturante (NDE) conduziu, a partir de estratégias participativas, o processo de RPP para ambos os CGTO, procurando contemplar demandas locorregionais, nacionais e internacionais advindas do campo da Terapia Ocupacional em relação com outros campos de saber e de prática.

Tendo em consideração experiências de revisão e atualização curriculares ${ }^{2-5}$, $o$ novo currículo dos CGTO foi reformulado segundo as regulamentaçóes profissionais nacionais, os posicionamentos da WFOT e as diretrizes do MEC para o Ensino Superior, conforme preconizado desde a criação do curso.

As justificativas para a reformulação foram: a necessidade de alinhamento com as políticas públicas nacionais, os campos de atuação profissional, os parâmetros nacionais e internacionais para formação do terapeuta ocupacional, e a evolução no campo do saber e da prática em Terapia Ocupacional, como, também, a necessidade de um processo reflexivo do grupo de docentes dos CGTO, após a avaliação do MEC, sendo, à época, a primeira validação para o curso do período noturno.

Sob todas essas consideraçóes, destacou-se a importância de haver um currículo flexível e a necessidade de maior integração entre os conteúdos advindos das ciências biológicas, sociais, humanas e da Terapia Ocupacional, bem como o redimensionamento da proporção de carga horária das disciplinas a elas relacionadas.

Além disso, teve-se em vista a adequação da quantidade de carga horária destinada às Atividades Formativas Complementares (AFC) e a articulação de ações de ensino, pesquisa e extensão, de maneira a envolver discentes em diferentes problemáticas sociais e adensar e aprofundar qualitativamente o processo de aprendizagem. E, ainda, a 
necessidade da integração dos cursos integral e noturno, por meio de um currículo que facilitasse a coordenação pedagógica frente ao corpo discente e docente, por meio da adequação da proposta curricular, para atender ao perfil dos cursos integral e noturno de forma paritária.

Também foram consideradas as mudanças político-institucionais (políticas de expansão universitárias, de inclusão e permanência) em consonância com o perfil dos estudantes ingressantes, a necessidade de implementação de estratégias para redução nos índices de retenção e evasão, e as mudanças no mercado de trabalho com novas possibilidades de inserção profissional do egresso de Terapia Ocupacional.

\section{O processo: a problematização do projeto pedagógico}

O NDE é responsável pelo acompanhamento, consolidação e atualização contínua do projeto pedagógico do curso. Suas atribuiçôes consistem em: contribuir para a consolidação do perfil profissional do egresso do curso; zelar pela integração curricular interdisciplinar entre as diferentes atividades de ensino presentes no currículo; indicar formas de incentivo ao desenvolvimento de atividades de pesquisa e extensão, tendo em vista as necessidades da graduação, as exigências do mercado de trabalho, as políticas públicas relativas à área de conhecimento do curso e o cumprimento das Diretrizes Curriculares Nacionais para os Cursos de Graduação ${ }^{6}$. No período da RPP, o NDE era composto pela coordenadora e a vice-coordenadora dos CGTO, seis docentes do DTO e uma docente do Departamento de Fisiologia.

Para a problematização do projeto pedagógico vigente, considerada a última avaliação de curso realizada pelo MEC, foi utilizada a metodologia ativa denominada Método do Arco de Maguerez. Este é constituído por cinco etapas: observação da realidade, pontos-chave, teorização, hipótese de solução e aplicação à realidade 7 . Para problematizar e planejar o processo de reformulação, partiu-se da seguinte pergunta: "Quais as potencialidades do Projeto Pedagógico vigente dos CGTO da UFPR e que mudanças são necessárias para superar suas limitaçôes frente às necessidades atuais para formação de terapeutas ocupacionais, de modo a fomentar sua reformulação, em especial, no que diz respeito à matriz curricular?”

De modo a apropriar-se da realidade do ensino de Terapia Ocupacional, a partir de setembro de 2013, foram realizados, pelo NDE, estudos de projetos pedagógicos de cursos no cenário nacional, com enfoque: na organização didático-pedagógica, distribuição de carga horária dos conteúdos curriculares, percurso formativo proposto na matriz curricular, atividades formativas complementares e metodologias de ensino.

Considerando a necessidade de participação e contribuição dos envolvidos na RPP, foram realizadas: reunióes pedagógicas com os docentes e técnicos de educação do DTO, fórum estudantil, reunióes com representação docente de outros departamentos envolvidos com os CGTO (Quadro 1), consultas à Pró-reitoria de Graduação (PROGRAD), estudos de viabilidade com a chefia do DTO, e reunióes de Colegiado dos CGTO (composto por representantes docentes e discentes). 
Quadro 1. Outros Departamentos envolvidos com os Cursos de Terapia Ocupacional

\begin{tabular}{|c|c|c|}
\hline Setor de Ciências da Saúde & Setor de Ciências Biológicas & Setor de Ciências Humanas \\
\hline Saúde Comunitária & Anatomia & Ciências Sociais \\
Cirurgia & Pioquímica & Psicologia \\
Medicina Forense e Psiquiatria & Fisiologia & \\
& Biologia Celular \\
& Patologia Básica & \\
\hline
\end{tabular}

Fonte: UFPR, $2016^{8}$

A participação estudantil ocorreu em dois encontros para esclarecimentos e discussão sobre a RPP, escuta de suas percepçôes e demandas referentes ao processo vivencial de formação profissional. Destacaram-se aqui: a dificuldade no cumprimento da carga horária de Atividades Formativas Complementares ( $\mathrm{AFC}^{(\mathrm{i})}$, a necessidade de antecipação de conteúdos específicos para fundamentação das atividades práticas, a carga horária excessiva de cunho biológico no primeiro ano, e o sábado como dia letivo (específico do curso noturno).

Os encontros com representantes dos departamentos vinculados ao curso serviram para apresentar o andamento do processo de reformulação e para a definiçãao de estratégias de mudança no que diz respeito à carga horária e periodização das unidades curriculares, proposição e integração de conteúdos.

As consultas à Pró-reitoria de graduação - PROGRAD versaram sobre as resoluçôes internas para reformulação de cursos (número de semanas letivas, incorporação da extensão como componente curricular, tutoria e orientação acadêmica, entre outros) e, nos encontros com a chefia do DTO, foram realizados estudos de viabilidade de implantação do novo projeto pedagógico, considerando os recursos humanos e a organização didático-pedagógica.

As reunióes pedagógicas com os docentes do DTO e técnicos em educação se concentraram na avaliação e definição dos conteúdos essenciais para a formação do terapeuta ocupacional de forma articulada e integrada, respeitando os marcos legais nacionais e internacionais e a realidade institucional. Para tanto, organizaram-se grupos de trabalho (GT) com intuito de fomentar reflexôes acerca das possibilidades de mudanças no PP vigente, em seus aspectos de caráter epistemológico, técnico-científico, pedagógico, estrutural e administrativo.

No planejamento da RPP, foram realizadas as seguintes discussóes temáticas, que se configuraram como pontos-chave do processo e direcionaram as etapas de teorização e de levantamento de hipóteses de solução:

- Pontos fortes e pontos fracos do projeto pedagógico de curso vigente;

- Premissas curriculares, objeto profissional e metodologias de ensino;

- Definição do perfil, identidade e objetivos do curso;

- Dinâmica "o curso que eu quero" - carga horária do curso, carga horária das AFC, número de semanas no semestre letivo (15, 18 ou 20), currículo único para os cursos integral e noturno, carga horária total de estágio e sua distribuição semestral e pósgraduação;

- Atividades práticas e estágios, considerando as possibilidades curriculares e sua distribuição no decorrer do processo formativo;

(i) De acordo com a Resolução nº 70/04-CEPE da UFPR, as Atividades Formativas são aquelas complementares ao eixo fundamental do currículo, objetivando sua flexibilização, e envolvem atividades de ensino como: monitoria, disciplinas eletivas, participação em projetos de pesquisa e/ou extensão, cursos livres com certificação, atividades de representação acadêmica, participação em eventos acadêmico-científicos, entre outras avaliadas e validadas por comissão responsável. 
- Natureza das disciplinas de acordo com resolução interna institucional (Padrão - PD, Laboratório - LB, Campo - CP, Orientada - OR, Prática Específica - PE e Estágio - ES) e rol de disciplinas optativas;

- Propostas e sugestóes para a matriz curricular, com ênfase na periodização e caracterização dos eixos verticais: Bases teóricas e fundamentos em Terapia Ocupacional; Prática profissional: métodos, abordagens e procedimentos; Produção de conhecimento em Terapia Ocupacional;

- Atividades de laboratório - LAB: caracterização terminológica, redefinição e conteúdos;

- Conjunto de disciplinas de Terapia Ocupacional aplicada: redefinição, caracterização e conteúdo;

- Reformulação de ementário.

Além dos GT ocorridos por ocasião das reuniôes pedagógicas, houve a disponibilização de arquivo virtual para contribuições dos docentes referentes aos ementários e conteúdos disciplinares, com posterior composição de um grupo de trabalho específico para compilação dos dados.

Com o andamento do processo, foram elaborados: a proposta de cooperação, intercâmbio e internacionalização, bem como o regulamento do programa de orientação acadêmica dos CGTO. Os demais regulamentos foram atualizados.

\section{Os fundamentos teóricos: objeto profissional e pressupostos curriculares}

O projeto pedagógico foi reformulado a partir da especificidade da Terapia Ocupacional e norteado pelo objeto de estudo e intervenção da profissão num caráter relacional com outros campos do conhecimento e práticas profissionais. Ele procurou contemplar: as diferentes visões, perspectivas, paradigmas que buscam compreender o homem, a sociedade, os processos saúde-doença e de inclusão/exclusão social que influenciam a forma de fazer ciência e atuar no campo da prática profissional, sendo estas fundamentais para o futuro profissional poder investigar, planejar, gerenciar e prestar assistência e cuidado a indivíduos e coletivos.

O processo de RPP dos CGTO possibilitou, aos envolvidos, o diálogo acerca dos fundamentos históricos, filosóficos e metodológicos da profissão, que garantem não apenas a especificidade de seu objeto, mas também sua legitimação social. Notou-se que, como apresenta Feriotti ${ }^{7}$, ao analisar o contexto de transição paradigmática da saúde e da ciência pela perspectiva da teoria da complexidade, o objeto de estudo da Terapia Ocupacional ganhou diferentes tratamentos, dependendo do contexto filosófico, cultural, científico e histórico de produção de conhecimento a partir do qual foi interpretado.

A concepção de "atividade humana" recebeu, no curso de desenvolvimento da profissão, diferentes enfoques, classificações e nomenclaturas (ação, fazer humano, práxis, ocupação, cotidiano, afazeres diários, dentre outros), estando, portanto, relacionada a diferentes teorias e métodos. Isso se explica porque, por sua complexidade, ela abre um vasto campo de estudo e de abordagens teóricas e técnicas, podendo ser vista por meio de diferentes facetas, ângulos e pontos de vista ${ }^{9}$ (p. 46). 
Considerando os atuais debates sobre os fundamentos e epistemologia da Terapia Ocupacional, levou-se em conta que o termo "atividade" é bastante adotado no cenário nacional e que o termo "ocupação" tem se destacado no contexto da discussão sobre a necessidade de uma terminologia própria à profissão, no bojo do processo de reconhecimento científico nacional e internacional e do fortalecimento da identidade da profissão ${ }^{10-12}$.

Sendo assim, considerou-se que "atividade" e "ocupação" são termos que podem assumir diferentes conceitualizações, dependendo dos quadros de referência teórico-metodológicos assumidos, denotando a multiplicidade dos saberes e práticas profissionais. Com opção terminológica por ocupação, adotou-se uma concepção de homem como ser ocupacional em sua diversidade e demandas biológicas, psicológicas, espirituais, socioculturais e ecológicas; e de mundo enquanto espaço/ambiente/ contexto onde esse ser ocupacional é concebido, desenvolve suas habilidades, transforma e é transformado no decorrer de sua existência para a autossatisfação e vida em sociedade.

Diante do cenário atual de debates sobre as diferentes formas de produção de conhecimento científico e seus impactos sociais, os envolvidos no processo de RPP decidiram que o projeto pedagógico deveria expressar o entendimento de que, independente da opção teórico-metodológica, o essencial ao profissional é o conhecimento do pluralismo no campo da ciência e a explicitação da linha de pensamento e da orientação epistemológica adotadas por ele.

A partir disso, deliberou-se que o projeto pedagógico deveria basear-se nos seguintes pressupostos:

- O terapeuta ocupacional é um agente de processos de mudança junto a indivíduos e coletivos;

- O ser humano como um ser ocupacional-relacional-contextual;

- A ocupação humana - ação humana - fazer humano - cotidiano como mediadores do desenvolvimento e conhecimento humano, tendo em vista os aspectos inerentes ao envolvimento em diferentes atividades e contextos de vida e enquanto objeto de investigação, avaliação e intervenção no campo da Terapia Ocupacional;

- A participação e o envolvimento em atividades/ocupaçóes como forma de expressão do homem e como potência para construção de processos existenciais, projetos de vida em direção à autonomia individual e coletiva, assim como suas influências no estabelecimento de significado para a vida no âmbito individual e social.

Eles foram, portanto, elaborados de modo que contemplassem articuladamente as diferentes visões, perspectivas e paradigmas científicos de forma a dotar o estudante de habilidades para o planejamento e gerenciamento da atenção, assistência e cuidado a indivíduos e coletivos que possuem dificuldade no seu fazer cotidiano, no engajamento/envolvimento/desempenho ocupacional e/ou na participação ativa na vida social. 


\section{A nova matriz curricular: eixos, ênfases e temas transversais}

A elaboração da matriz curricular proposta orientou-se pelas Diretrizes Curriculares Nacionais para o Curso de Graduação em Terapia Ocupacional estabelecidas pela Resolução CNE/CES 6 de 2002(j), considerando as habilidades e competências necessárias para a prática profissional elencadas em seus artigos $4^{\circ}$ e 5‥ Considerando o núcleo profissional da TO, enquanto aspecto central e portador de sua especificidade, destacam-se algumas das habilidades e competências descritas nas $\mathrm{DCNTO}^{13}$, que podem ser entendidas como centrais no processo formativo:

Conhecer os fundamentos históricos, filosóficos e metodológicos da Terapia Ocupacional e seus diferentes modelos de intervenção;

Compreender o processo de construção do fazer humano, isto é, de como o homem realiza suas escolhas ocupacionais, utiliza e desenvolve suas habilidades, se reconhece e reconhece a sua ação;

Conhecer, experimentar, analisar, utilizar e avaliar a estrutura e dinâmica das atividades e trabalho humano, tais como: atividades artesanais, artísticas, corporais, lúdicas, de lazer, cotidianas, sociais e culturais;

Identificar, entender, analisar e interpretar as desordens da dimensão ocupacional do ser humano, e utilizar, como instrumento de intervenção, as diferentes atividades humanas, quais sejam: as artes, o trabalho, o lazer, a cultura, as atividades artesanais, o autocuidado, as atividades cotidianas e sociais, dentre outras.

Considerando a noção de competência ${ }^{4,5}$ para além de uma perspectiva racionalista, utilitária e pragmática, partiu-se da compreensão de que o processo formativo se delineia a partir de conhecimentos para o exercício de habilidades, atitudes e valores expressos na evolução do raciocínio profissional e necessários para o perfil de egresso estabelecido. Tem-se por finalidade a formação de terapeutas ocupacionais com: capacidade técnico-cientifica, ética e política para o exercício profissional, em diferentes funçôes e cenários de prática nos âmbitos da saúde, educação, social, da cultura, entre outros, de caráter público ou privado ${ }^{8}$.

A partir de tal entendimento, a matriz se organizou em temas transversais e em eixos e ênfases formativos, seguindo a periodização do curso (Figura 1). Os três eixos, (1) Bases teóricas e fundamentos da Terapia Ocupacional; (2) Prática Profissional: métodos, abordagens e procedimentos técnico-assistenciais, e (3) Produção de conhecimento, norteiam verticalmente a trajetória discente, com intuito de favorecer a integração conceitual e metodológica e fortalecer a produção de conhecimento. As ênfases visam orientar a articulação horizontal e propiciar um panorama gradativo de formação profissional envolvendo processos de aproximação, observação, reflexão, compreensão, análise crítica e proposição teórico-prática (Quadro 2).

Os aspectos centrais considerados na elaboração das ênfases do percurso formativo discente foram: conhecimento e contextualização de cenários de prática, desenvolvimento de habilidades, atitudes e valores, e formação de identidade profissional.

Como temas transversais para nortear o desenvolvimento de atividades de ensinopesquisa-extensão foram definidos: "Ética, Justiça e Direitos Humanos”; "Diversidade étnico-racial e cultural"; "Territorialidade, desenvolvimento e sustentabilidade". Eles seguiram os posicionamentos da WFOT sobre: o respeito à cultura e à valorização da diversidade, a ética e os direitos humanos, a inclusão e as possibilidades equitativas de participação, e a sustentabilidade ambiental ${ }^{1416}$.

(j) A atual resolução encontrase em processo de avaliação e discussão conduzido pela Rede Nacional de Ensino e Pesquisa em Terapia Ocupacional (RENETO), tendo em vista o Projeto de Lei 7.647/2010 e a ampliação das possibilidades de inserção do terapeuta ocupacional vinculado a políticas públicas de áreas como: saúde, assistência social, justiça, educação e cultura. A entidade organizou, em agosto de 2017, o $1^{\circ}$ Seminário de Revisão das Diretrizes Curriculares Nacionais, e abriu uma Consulta Pública (entre os meses de agosto e dezembro de 2017) para sugestões e contribuições advindas de colegiados de curso das Instituições de Ensino Superior, com intuito de dar seguimento à proposta de reformulação das Diretrizes Curriculares Nacionais do Curso de Graduação em Terapia Ocupacional. 
(2)

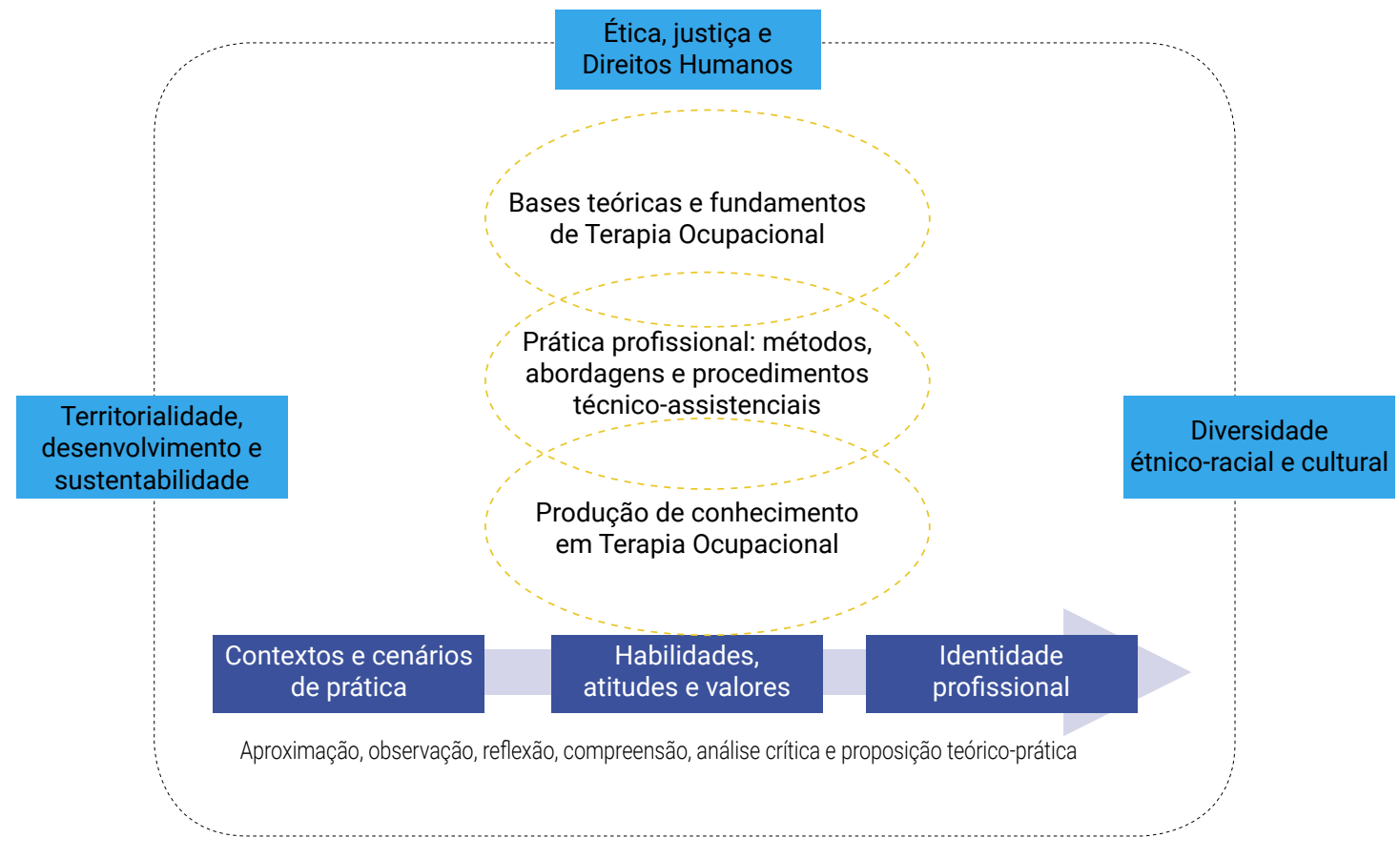

Figura 1. Concepção do percurso formativo: eixos, ênfases e temas transversais

Fonte: Os autores, 2018.

Quadro 2. Ênfases do percurso formativo

\begin{tabular}{|c|l|}
\hline SEMESTRE & \multicolumn{1}{c|}{ ÊNFASE } \\
\hline $1^{\circ}$ e $2^{\circ}$ & Aproximação do objeto, cenários e práticas profissionais \\
\hline $3^{\circ}$ e $4^{\circ}$ & $\begin{array}{l}\text { Desenvolvimento de habilidades de observação sistematizada } \\
\text { Aproximação mais crítica, reflexiva com as práticas específicas de TO. } \\
\text { Conhecimento da rede privada e dos diferentes sistemas públicos, como por exemplo: } \\
\text { Sistema Único de Saúde, Sistema Único de Assistência Social, Educação, Justiça, Traba- } \\
\text { lho, Cultura, entre outros }\end{array}$ \\
\hline $5^{\circ}$ e $6^{\circ}$ & $\begin{array}{l}\text { Estímulo e desenvolvimento do raciocínio profissional } \\
\text { Compreensão de métodos, ferramentas, dispositivos e aspectos éticos/deontológicos no } \\
\text { Processo de Terapia Ocupacional } \\
\text { Reflexão sobre a formação de identidade profissional } \\
\text { Capacidade de contextualizar e integrar conhecimentos }\end{array}$ \\
\hline $7^{\circ}$ e $8^{\circ}$ & $\begin{array}{l}\text { Desenvolvimento de habilidades e competências para planejamento } \\
\text { e condução do Processo de TO de forma supervisionada } \\
\text { Início do desenvolvimento de identidade profissional }\end{array}$ \\
\hline $9^{\circ}$ e $10^{\circ}$ & $\begin{array}{l}\text { Aprimoramento de habilidades e competências para planejamento e condução do Proces- } \\
\text { so de TO de forma supervisionada } \\
\text { Desenvolvimento de identidade profissional }\end{array}$ \\
\hline
\end{tabular}

Fonte: UFPR, $2016^{8}$

Os temas transversais procuram também responder às diretrizes do MEC de inclusão, no Ensino Superior: das temáticas dos direitos humanos, educação ambiental e respeito à diversidade de pessoas, grupos e territórios, de modo a contribuir com a promoção do desenvolvimento, da justiça social, da democracia, da cidadania e da $\operatorname{paz}^{17-19}$. 
Com efeito, a legislação preconiza o compromisso das universidades públicas com a promoção dos direitos humanos na direção de uma sociedade livre e aberta às diferenças: étnico-raciais, territoriais, religiosas, culturais, físico-individuais, de gênero, geracionais, de orientação sexual, opção política, nacionalidade e outras ${ }^{19}$. Também reforça o compromisso ético-político de construção de valores culturais baseados na justiça social e na qualidade ambiental e de vida coletiva, de modo a contribuir com a consolidação de um modelo social sustentável ${ }^{20}$.

Considerando o exposto, a matriz curricular buscou orientar a formação tendo em vista o desenvolvimento do pensamento crítico-reflexivo e de saberes técnico-científicos de forma alinhada às políticas públicas relacionadas à população atendida, em suas diferentes fases de vida, na garantia de direitos fundamentais, na participação e inclusão sociais, visando à justiça sócio-ocupacional.

\section{Aplicação à realidade: resultados do processo}

O processo de reformulação da matriz curricular resultou na redução da carga horária total do curso de 3915 horas para 3305 horas, tendo impacto principal nas AFC. As disciplinas permaneceram na modalidade semestral, com calendário acadêmico de 15 semanas, mas o tempo de integralização dos CGTO passou de nove para dez semestres, devido à necessidade de retirar a carga horária de sábado pela manhã do curso noturno e propiciar a concentração de disciplinas em um único período (Quadro 3).

A reorganização didático-pedagógica incluiu a diminuição de carga horária de algumas disciplinas e a alteração na periodização dos conteúdos referentes às Ciências Biológicas, acolhendo tanto as demandas de discentes como de docentes no tocante à antecipação de conteúdos específicos de Terapia Ocupacional, permitindo maior aproximação do estudante aos cenários de prática profissional.

Quadro 3. Distribuição de carga horária dos conteúdos dos CGTO segundo as DCNTO

\begin{tabular}{|l|c|c|}
\hline \multicolumn{1}{|c|}{ Conteúdos dos CGTO } & Carga horária anterior (h) & Carga horária nova (h) \\
\hline Ciências Biológicas e da Saúde & 555 & 495 \\
\hline Ciências Sociais e Humanas & 315 & 330 \\
\hline Ciências da Terapia Ocupacional & 1530 & 1200 \\
\hline Estágio & 795 & 810 \\
\hline Núcleo optativo & 30 & 120 \\
\hline Atividades Formativas Complementares & 660 & 200 \\
\hline Trabalho de Conclusão de Curso & 30 & 150 \\
\hline Total & 3915 & 3305 \\
\hline
\end{tabular}

Fonte: Os autores, 2018.

Os conteúdos específicos de formação prática (estágios, laboratórios e prática específica) totalizaram 1230 horas. A distribuição da carga horária de estágio foi revisada tendo em vista: maior vivência nos contextos de prática pelos estudantes do quarto ano, uma transição mais suave de carga horária semanal entre o quarto e o último ano, também em razão da disponibilidade de preceptores/supervisores. A carga horária total de estágio mudou de 795 horas para 810 horas, sendo as cargas horárias 
semanais e os semestres alterados de quatro horas ( $6^{\circ}$ e $7^{\circ}$ semestres) para nove horas ( $7^{\circ}$ e $8^{\circ}$ semestres), e de $22 / 23$ horas ( $8^{\circ}$ e $9^{\circ}$ períodos) para 16 horas ( $9^{\circ}$ e $10^{\circ}$ semestres).

O conjunto de disciplinas antes denominado "Terapia Ocupacional Aplicada" foi redimensionado para "Processo de Terapia Ocupacional", propondo, com isso, maior enfoque no desenvolvimento e fundamentação do raciocínio profissional no que diz respeito aos métodos, abordagens e procedimentos dos diferentes campos/contextos de prática. Os demais conteúdos obrigatórios ministrados pelo Departamento de Terapia Ocupacional (DTO) foram pensados de modo a proporcionarem a articulação entre os conteúdos gerais e específicos essenciais à formação teórico-prática, científica e profissional.

A carga horária destinada aos conteúdos optativos aumentou de trinta para 120 horas. Sendo incluídas disciplinas antes configuradas como obrigatórias (Psicomotricidade e Análise Ergonômica do Trabalho), mantidas as optativas da proposta anterior (Arteterapia, Comunicação em Língua de Sinais Brasileira, Cuidados Paliativos e Tópicos Especiais em Terapia Ocupacional) e acrescentadas novas unidades curriculares (Terapia Ocupacional, Movimentos Populares e Controle Social; Humanidades e Terapia Ocupacional; Métodos, Abordagens e Procedimentos em Terapia Ocupacional II, Classificação Internacional de Funcionalidade, Incapacidade e Saúde e Antropologia da Saúde). Foram focalizados os conteúdos das Ciências Humanas e Sociais e Métodos, Abordagens e Procedimentos Profissionais.

A ampliação de carga horária de conteúdos optativos considerou: a possibilidade do direcionamento do percurso formativo, maior aprofundamento em temas específicos e uma formação diversificada e interdisciplinar por meio do aprendizado de novos conhecimentos e convívio com docentes e discentes da mesma área e/ou afins.

Sobre as bases teórico-metodológicas da profissão, o que se teve por horizonte foi: a ampliação de conteúdos de fundamentos de Terapia Ocupacional no início da formação, como base para as atividades práticas, assim como a inserção de debates sobre as atuais tendências epistemológicas da profissão, a reflexão sobre a formação e identidade profissional na contemporaneidade.

\section{A proposta pedagógica: uma aposta na diversidade}

Segundo Veiga ${ }^{21}$, a formação de professores para a Educação Superior apresenta questões contemporâneas, como: a ampliação do número de cursos e vagas no Ensino Superior e desafios para o exercício da prática pedagógica. A autora cita como questóes a se equacionarem: a ampliação dos cursos nas universidades de Ensino Superior, com aumento do quadro docente sem experiência, e a ausência de políticas institucionais de formação pedagógica e desenvolvimento profissional, além da heterogeneidade do corpo discente que, segundo o que se tem observado na prática e os resultados das políticas avaliativas, tem apresentado dificuldades e desempenho insuficientes.

A docência é uma atividade complexa porque se insere em relações sociais e históricas. Ela demanda do professor habilidades de reflexão crítica sobre a prática pedagógica e a compreensão de sua natureza dinâmica, possibilidades e limites, rompendo com a forma transmissiva de ensinar. Além disso, considerando a indissociabilidade entre ensino, pesquisa e extensão, o docente precisa ser um 
articulador entre os diferentes componentes curriculares e as propostas de intervenção que estruturam os projetos pedagógicos dos cursos de graduação e de pós-graduação ${ }^{21}$.

Daí a importância da diversidade de metodologias de ensino participativas, problematizadoras e dialógicas, capazes de realizar a articulação de conteúdos e garantir condiçôes para que o aluno se responsabilize de modo cada vez mais autônomo por seu processo formativo ${ }^{21}$.

A proposta do Curso de Terapia Ocupacional da UFPR é acolher a diversidade de metodologias de ensino já utilizadas pelos docentes, com destaque às de caráter dialógico e problematizador, considerando o repertório intelectual e vivencial prévio do estudante, assim como a opção pela utilização de múltiplas estratégias pedagógicas (debates, seminários, estudos de caso, entrevistas, visitas técnicas, diários de campo, portfólios, elaboração de projetos de intervenção, entre outras) e de recursos e materiais de veiculação de informação variados (livros, artigos científicos, vídeos e documentários, entre outros).

As formas de avaliação seguem a mesma lógica de multiplicidade de estratégias, sejam elas processuais ou não, com enfoque na capacidade de articulação entre teoria e prática e na valorização da criticidade, criatividade e autonomia do estudante.

Um processo formativo humanista, crítico-reflexivo e ético - baseado na apropriação e produção do conhecimento pelo estudante e no desenvolvimento de competências e habilidades que o preparem plenamente para a vida cidadã e profissional - deve basear-se em estratégias metodológicas ativas que privilegiem os princípios de indissociabilidade das funções de ensino, pesquisa e extensão, integração entre teoria e prática, interdisciplinaridade e flexibilidade, entre outros.

Assim, para o alcance dos objetivos do curso, as metodologias de ensino propostas fundamentaram-se na integração dos eixos curriculares e na interação entre teoria e prática desde o início do curso, de forma a conduzir o percurso acadêmico na flexibilização curricular por meio das AFC e na incorporação das atividades de pesquisa e extensão no processo de ensino/aprendizagem.

\section{Os desafios}

Como afirmam Pan e Lopes ${ }^{22}$, a adesão ao REUNI contribuiu para a ampliação do acesso ao Ensino Superior e, no caso da Terapia Ocupacional, para o aumento significativo de cursos públicos no país. Por outro lado, há que se reconhecerem as dificuldades existentes devido à falta de recursos humanos e/ou infraestrutura que, por vezes, limitam o pleno desenvolvimento dos projetos pedagógicos e um maior investimento no âmbito da pesquisa e extensão.

Como apresentado em estudos sobre projetos pedagógicos, o processo de reformulação curricular demanda também: o reconhecimento das possibilidades e limites existentes dentro da própria estrutura universitária, a articulação com instâncias superiores e departamentos distintos, e a disponibilidade e a abertura do corpo docente em percorrer o caminho proposto, levando em conta tensionamentos e inquietaçóes existentes diante da diversidade de perspectivas teórico-metodológicas ${ }^{3,5}$.

Os desafios a enfrentar a partir de agora são: a formação docente continuada em metodologias de Ensino Superior e a atualização dos saberes próprios à profissão, além da reflexão constante sobre a própria formação e práticas didático-assistenciais. A docência para sessenta alunos em sala de aula também tem exigido o conhecimento 
de metodologias que garantam a qualidade do ensino e o acompanhamento de cada discente em seu processo formativo.

Uma formação afinada às políticas públicas e a ampliação dos campos de prática para serviços das redes de atenção em saúde, proteção social, educação e cultura; os limites do cenário local quanto à oferta de serviços para estágios e preceptorias; a concentração das atividades práticas na clínica-escola para os estudantes do curso noturno, e as possibilidades de ampliação e integração das atividades de pesquisaextensão ao ensino são pautas constantes nas reuniões pedagógicas departamentais, e têm demandado ações estratégicas entre o Departamento de Terapia Ocupacional e a Coordenação do Curso.

Que o discente consiga participar de atividades de extensão e pesquisa e que desenvolva competências para leitura, interpretação e produção de trabalhos científicos, bem como o fomento à produção científica já na graduação, com vistas à futura inserção dos egressos em cursos de pós-graduação (stricto sensu), são também horizontes vislumbrados.

De acordo com Jurdi et al. ${ }^{5}$, há necessidade de mudança de paradigma para uma formação interdisciplinar e interprofissional. Ressaltam também que as formações em Terapia Ocupacional no Brasil ainda privilegiam conteúdos das Ciências Biológicas e da Saúde em detrimento das Humanidades.

Pan e Lopes ${ }^{22}$, em sua pesquisa sobre as políticas de Ensino Superior e a graduação em Terapia Ocupacional, reiteram essa distribuição superior de carga horária destinada aos conteúdos das Ciências Biológicas e da Saúde nos currículos analisados. Destacam, portanto, a necessidade de se discutir e ponderar sobre os conteúdos indispensáveis à formação do terapeuta ocupacional, assim como seus níveis de aprofundamento, de modo que sejam considerados o perfil profissional esperado e as diferentes áreas de atuação profissional.

Essa ampliação de conteúdos derivados das Ciências Humanas continua sendo um desafio para o Curso de Terapia Ocupacional da UFPR, pela dificuldade, de acordo com os departamentos ministrantes desses conteúdos, e a viabilidade de serem ministrados pelos docentes do departamento de Terapia Ocupacional. Ademais, tornase necessária ainda a avaliação de como a inclusão desses conhecimentos redimensiona os saberes e as práticas profissionais, o raciocínio terapêutico-ocupacional nos processos de assistência e prestação de serviços.

De igual modo, a orientação pelas atuais políticas educacionais voltadas à educação em direitos humanos e a afirmação da história e cultura de grupos sociais específicos ${ }^{23,24}$, bem como a inclusão dos temas transversais elencados no projeto pedagógico nas atividades de ensino-pesquisa e extensão, apresentam-se como desafios a serem enfrentados pelo corpo docente, a fim de serem efetivados e articulados nos processos de ensino-aprendizagem.

\section{Considerações finais}

Em um momento de reflexão e discussão sobre as diretrizes para a formação em Terapia Ocupacional, a reformulação curricular buscou oferecer, dentro da realidade e possibilidades, uma formação pautada em saberes e práticas alicerçados na perspectiva 
da ciência e dos conhecimentos nos diferentes campos de saber, das novas tecnologias e do cenário profissional, de modo pertinente e contextualizado.

O percurso inicial de estudos de diferentes projetos pedagógicos no cenário brasileiro contribuiu para a problematização e análise da nossa realidade, levando em consideração as particularidades referentes: ao número de discentes, configuração de corpo docente, estrutura administrativa, campos de estágio, projetos de pesquisa e extensão, e uma organização curricular que ampliasse as oportunidades de integração das atividades de ensino-pesquisa-extensão.

A integração necessária dos agentes envolvidos para levar a cabo as discussóes, negociações e encaminhamentos tanto referentes a aspectos didáticos-administrativos como teóricos-metodológicos, com seus distintos posicionamentos, é um constante exercício de construir pontes de diálogo, de modo a trilhar os caminhos de mudança propostos.

Com o novo currículo sendo implantado desde o primeiro semestre de 2017, o desafio é realizar uma interlocução constante com a comunidade interna e externa à universidade, bem como criar oportunidades para o envolvimento e engajamento de discentes, egressos, docentes, técnicos e demais agentes envolvidos na formação e nas atividades de ensino-pesquisa-extensão do CGTO, procurando responder: às mudanças paradigmáticas no campo da ciência, às características do mercado de trabalho e às diferentes possibilidades de inserção profissional.

Sobretudo, o processo de implantação curricular demanda o acompanhamento contínuo pelo Colegiado de Curso e o NDE, de forma a identificar necessidades de ajustes e adequaçôes, à medida que a proposta se efetiva, sendo a definição e o planejamento do método de avaliação do PPC indispensáveis para uma formação acadêmica de qualidade e o alcance do perfil de egresso esperado.

\section{Autores (continuação)}

\section{Regina Celia Titotto Castanharo(g)} <prof.retitotto@ufpr.br> (iD

Rita Aparecida Bernardi Pereira(h) <rita.pereira@ufpr.br>

\section{Contribuições dos autores}

Todos os autores participaram da discussão dos resultados, da revisão e da aprovação da versão final do manuscrito coordenadas pelas duas primeiras autoras.

\section{Direitos autorais}

Este artigo está licenciado sob a Licença Internacional Creative Commons 4.0, tipo BY (https://creativecommons.org/licenses/by/4.0/deed.pt_BR). 


\section{Referências}

1. Universidade Federal do Paraná. Plano de desenvolvimento institucional da Universidade Federal do Paraná - PDI UFPR 2012-2016. Curitiba: Pró-Reitoria de Planejamento, Orçamento e Finanças, Coordenadoria de Planejamento Institucional; 2012.

2. Drummond AF, Rodrigues AMVN. Os desafios da implantação de uma proposta de flexibilização curricular nos cursos de terapia ocupacional. Rev Ter Ocup USP. 2004; 15(3):106-11.

3. Furlan PG, Ribeiro HM, Meneses KVP, Campos IO, Rodrigues LMMA. A formação profissional de terapeutas ocupacionais e o curso de graduação da Universidade de Brasília, Faculdade de Ceilândia. Cad Ter Ocup UFSCar. 2014; 22(1):109-19.

4. Barba PCSD, Silva RF, Joaquim RHVT, Brito CMD. Formação inovadora em terapia ocupacional. Interface (Botucatu). 2012; 16(42):829-42.

5. Jurdi APS, Nicolau SM, Figueiredo LRU, Rossit RAS, Maximino VS, Borba PLO. Revisitar processos: revisão da matriz curricular do curso de terapia ocupacional da Universidade Federal de São Paulo. Interface (Botucatu). 2018; 22(65):527-38.

6. Universidade Federal do Paraná. Resolução no 34/11 CEPE . Altera a Resolução 75/09-CEPE que institui os Núcleos Docentes Estruturantes no âmbito da estrutura de gestão acadêmica dos Cursos Graduação - Bacharelado, Licenciatura e Cursos Superiores de Tecnologia da Universidade Federal do Paraná. Curitiba: UFPR; 2011.

7. Colombo AA, Berbel NA. A metodologia da problematização com o arco de Maguerez e sua relação com os saberes de professores. Semina Cienc Soc Hum. 2007; 28(2):121-46.

8. Universidade Federal do Paraná. Projeto pedagógico do curso de terapia ocupacional. Curitiba: UFPR; 2016.

9. Feriotti ML. Construção de identidade(s) em terapia ocupacional no contexto das transformações paradigmáticas da saúde e da ciência. In: Feriotti ML, Pádua EMM. Terapia ocupacional e complexidade: práticas multidimensionais. Curitiba: Editora CRV; 2013.

10. Lima EMFA, Okuma DG, Pastore MN. Atividade, ação, fazer e ocupação: a discussão dos termos na terapia ocupacional brasileira. Cad Ter Ocup UFSCar. 2013; 21(2):24354.

11. Magalhães L. Ocupação e atividade: tendências e tensôes conceituais na literatura anglófona da terapia ocupacional e da ciência ocupacional. Cad Ter Ocup UFSCar. 2013; 21(2):255-63.

12. Salles MM, Matsukura T. Estudo de revisão sistemática sobre o uso do conceito de cotidiano no campo da terapia ocupacional no Brasil. Cad Ter Ocup UFSCar. 2013; 21(2):265-73.

13. Ministério da Educação (BR). Resolução CNE/CES no 6, de 19 de Fevereiro de 2002. Institui diretrizes curriculares nacionais do curso de graduação em terapia ocupacional. Brasília, DF: MEC; 2002.

14. World Federation of Occupational Therapists. Position statement on human rights. Londres: WFOT; 2006.

15. World Federation of Occupational Therapists. Position statement on diversity and culture. Londres: WFOT; 2010. 
16. World Federation of Occupational Therapists. Position statement on environmental sustainability sustainable practice within occupational therapy. Londres: WFOT; 2012.

17. Presidência da República (BR). Lei no 9.795, de 27 de Abril de 1999. Dispóe sobre a educação ambiental, institui a Política Nacional de Educação Ambiental e dá outras providências. Brasília, DF: Casa Civil; 1999.

18. Ministério da Educação (BR). Resolução no 1, de 17 de Junho de 2004. CNE/CPInstitui diretrizes curriculares nacionais para a educação das relaçóes étnico-raciais e para o ensino de história e cultura afro-brasileira e africana. Brasília, DF: MEC; 2004.

19. Ministério da Educação (BR). Plano Nacional de Educação em Direitos Humanos / Comitê Nacional de Educação em Direitos Humanos. Brasília, DF: Secretaria Especial dos Direitos Humanos, Ministério da Educação, Ministério da Justiça, UNESCO; 2007.

20. Ministério do Meio Ambiente (BR). Programa Nacional de Educação Ambiental. Educação ambiental: por um Brasil sustentável. PRONEA, marcos legais e normativos. 4a ed. Brasília, DF: Ministério do Meio Ambiente, Ministério da Educação; 2014.

21. Veiga IPA. Formação de professores para a educação superior e a diversidade da docência. Rev Dialogo Educ (Curitiba). 2014; 14(42):327-42.

22. Pan LC, Lopes RE. Políticas de ensino superior e a graduação em terapia ocupacional nas instituiçôes federais de ensino superior no Brasil. Cad Ter Ocup UFSCar. 2016; 24(3):457-68.

23. Câmara dos Deputados (BR). Lei no 11.645, de 10 Março de 2008. Altera a Lei no 9.394, de 20 de Dezembro de 1996, modificada pela Lei no 10.639, de 9 de Janeiro de 2003, que estabelece as diretrizes e bases da educação nacional, para incluir no currículo oficial da rede de ensino a obrigatoriedade da temática história e cultura afrobrasileira e indígena. Diário Oficial da União. 11 Mar 2008; sec 1.

24. Ministério da Educação (BR). Resolução CNE/CP no 1, de 30 de Maio de 2012. Estabelece diretrizes nacionais para a educação em direitos humanos. Brasília, DF: MEC; 2012.

This article describes the process of curricular reformulation of the Occupational Therapy Course of the Federal University of Paraná that took place between 2013 and 2016. The reasons for the reformulation were the need to adapt to current national public policies and national and international parameters for professional education. The process was based on a participatory and problem-raising methodology, culminating in a curricular matrix defined by specific axes and emphases, with 3,305 hours distributed over five years. The pedagogical proposal took into account the theoretical-practical and didactic-methodological diversity of professors. It also considered the specificity of evening classes, the profile of entry-level students, the need to reduce retention and dropout rates, and changes in the labor market. The current challenge is the gradual implementation and ongoing evaluation of the new curriculum to ensure the expected education.

Keywords: Curriculum. Occupational therapy. Higher education. 
Este artículo relata el proceso de reformulación curricular del Curso de Terapia Ocupacional de la Universidad Federal de Paraná realizado en el período de 2013 a 2016. Las justificativas para la reformulación fueron la necesidad de alineamiento con las actuales políticas públicas nacionales y los parámetros nacionales e internacionales para formación profesional. El proceso ocurrió de forma participativa y de problematización, culminando en una matriz curricular delineada por ejes y énfasis específicos, con 3.305 horas distribuidas en cinco años. La propuesta pedagógica incluye la diversidad teórico-práctica y didáctico-metodológica de los docentes. También se consideró la especificidad de la formación en período nocturno, el perfil de los estudiantes entrantes, la necesidad de reducción en los índices de retención y evasión y los cambios en el mercado de trabajo. Ahora, el desafío es la implantación gradual y la evaluación continuada del nuevo currículo, para garantizar la formación esperada.

Palabras clave: Currículo. Terapia ocupacional. Enseñanza superior. 